\title{
Optical Properties of Plastically Deformed Copper
}

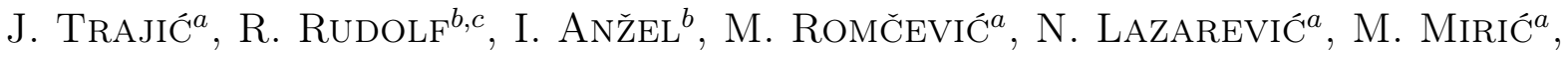 \\ Z. LAZAREVIĆ ${ }^{a}$, B. HADŽIĆ ${ }^{a}$ AND N. ROMČEVIĆ $\check{C}^{a, d, *}$ \\ ${ }^{a}$ Institute of Physics, Pregrevica 118, 11080 Belgrade, Serbia \\ ${ }^{b}$ Faculty of Mechanical Engineering, University of Maribor, 2000 Maribor, Slovenia \\ ${ }^{c}$ Zlatara Celje d.d., Kersenikova 19, 3000 Celje, Slovenia \\ ${ }^{d}$ Kristal infiz d.o.o., 11080 Belgrade, Serbia
}

\begin{abstract}
Pure copper (99.99), prepared in the sample of square cross-section $\left(10 \times 10 \mathrm{~mm}^{2}\right)$ and length about $50 \mathrm{~mm}$, was extremely plastically deformed with the repeated application of Equal Channel Angular Pressing (ECAP). ECAP was applied as an effective technique for producing bulk nano-scaled structures. Optical properties of the sample were investigated using Raman spectroscopy. Two types of lines: narrow (with width of $\approx 7 \mathrm{~cm}^{-1}$ ) and wide $\left(\approx 40 \mathrm{~cm}^{-1}\right)$ are registered. Existence of two types of lines indicates that in the specimen exists nano-sized crystal structures of both $\mathrm{Cu}$ and $\mathrm{CuO}$ related with three dimensional amorphous boundary spaces, which indicates that plastic deformation of the sample did not lead to total amorphisation of the specimen.
\end{abstract}

PACS numbers: 78.20-e, 78.30.j, 78.40.kc

\section{Introduction}

Hydrometallurgical extraction of metals is a branch of industry for which the research work is ongoing to develop processes which are less costly, more environmentally friendly and acceptable economically. Copper is used in vast variety of products in domestic and industrial domains as thermal and electrical conductor and as a constituent of various metal alloys [1]. Copper is second only to silver in its ability to conduct electricity. Due to this property, copper widely has been used as electrode in electrochemical studies [2]. Copper is easily worked, being both ductile and malleable. The ease with which it can be drawn into wire makes it useful for electrical work in addition to its excellent electrical properties. Copper can be machined, although it is usually necessary to use an alloy for intricate parts, such as threaded components, to get really good mach inability characteristics. Good thermal conduction makes it useful for heat sinks and in heat exchangers. Copper has good corrosion resistance, but not as well as gold. It has excellent brazing and soldering properties and can also be welded, although best results are obtained with gas metal arc welding [3].

Copper has a reddish, orangish, or brownish color because a thin layer of tarnish (including oxides) gradually forms on its surface when gases (especially oxygen) in the air react with it. But pure copper, when fresh, is actually a pinkish or peachy metal. Copper, cesium and gold are the only three elemental metals with a natural

* corresponding author; e-mail: romcevi@ipb.ac.rs color other than gray or silver [4]. The usual gray color of metals depends on their electron sea that is capable of absorbing and re-emitting photons over a wide range of frequencies. Copper has its characteristic color because of its unique band structure.

In this paper we will present results of Raman measurements of plastically deformed copper. Raman spectroscopy was used in order to determine structural characteristic because its gives local environments.

\section{Sample characterization}

Pure copper sample (99.99) prepared as the specimen of square cross-sections $\left(10 \times 10 \mathrm{~mm}^{2}\right)$ and of length of about $50 \mathrm{~mm}$ was extremely plastically deformed with repeated application of ECAP. ECAP, which is known as one of discontinuous processes of severe plastic deformation was applied as an effective technique for producing bulk nano-scaled structures. It is well known that severe plastic deformation of metallic materials often leads to microstructure with ultrafine grains and cross section that remain almost equal before and after deformation.

The experiments were performed in our experimental hydraulic press (VEB WEMA 250 MP) equipped with tool for ECAP. The tool consists of two intersecting channels of the same cross section $\left(10 \times 10 \mathrm{~mm}^{2}\right)$ that meet at angle $2 \Phi=90^{\circ}$. The geometry of tool provides that the material is deformed by simple shear at ideal, frictionless conditions. The cross section of the specimen remains almost equal before and after each step of the process, thus it is possible to subject one specimen several times to ECAP in order to reach high degrees of 
plastic deformation. In our case the sample of pure copper was subjected eight times to the ECAP process at room temperature $\left(20^{\circ} \mathrm{C}\right)$. This processing performed at low homologous temperatures leaded to a subdivision of the initially coarse grained microstructure into a hierarchical system of cell blocks and dislocation cells.

For microstructure investigation two samples were prepared: $\mathrm{Cu} 1.1$ P-cross section surface, $\mathrm{Cu} 1.2 \mathrm{~V}$ -longitudinal section surface. The surfaces of the samples have been investigated using atomic force microscopy (AFM). Figures 1a and 1b show typical topological morphology in two directions (longitudinal and transverse). On the transverse surface more particles contour can be seen, which probably correspond to the nano-sized crystalline phases. Contrary to this, on the longitudinal surface there are essentially less phases which could be compared to the formed phases on the transverse surface.

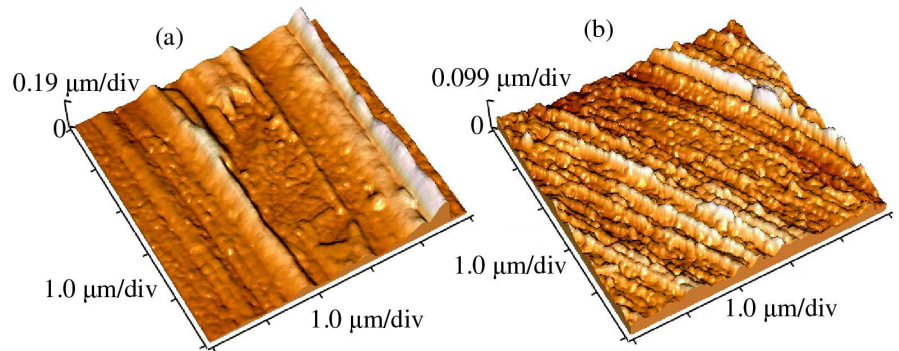

Fig. 1. AFM image of surface of the (a) $\mathrm{Cu} 1.2 \mathrm{~V}$; (b) $\mathrm{Cu} 1.1 \mathrm{P}$ sample.

\section{Raman measurements}

The micro-Raman spectra were taken in the backscattering configuration and analyzed by Jobin Yvon T64000 spectrometer, equipped with nitrogen cooled charge-coupled-device detector. As excitation source we used the $514.5 \mathrm{~nm}$ line of an Ar-iron laser. The measurements were performed at different laser power.

Pure copper, in principle crystallized in the face centered cubic type structure $\left(O_{h}\right.$ space group symmetry), and the first order Raman modes are not active. However, plastic deformation of sample as well as penetration of oxygen in sample (and creating $\mathrm{CuO}$ ) causes appearance of Raman active modes. Factor group analysis for $\mathrm{CuO}$ yields [5]:

$$
\begin{aligned}
& \mathrm{Cu}\left(C_{i}\right): \Gamma=3 A_{u}+3 B_{u}, \\
& \mathrm{O}\left(C_{2}\right): \Gamma=A_{g}+2 B_{g}+A_{u}+2 B_{u}, \\
& \Gamma_{\mathrm{CuO}}=A_{g}+2 B_{g}+4 A_{u}+5 B_{u} .
\end{aligned}
$$

$1 A_{u}\left(T_{y}\right)$ and $2 B_{u}\left(T_{x}, T_{z}\right)$ are acoustical modes, so that the total of vibrational modes $(\boldsymbol{q}=0)$ and their activity is:

$$
\Gamma_{\mathrm{CuO}}^{\mathrm{vib}}=A_{g}(R)+2 B_{g}(R)+3 A_{u}(i r)+3 B_{u}(i r) .
$$

Thus, three Raman $\left(A_{g}, B_{g}\right)$ and six infrared $\left(A_{u}, B_{u}\right)$ active modes are to be expected in the spectra of $\mathrm{CuO}$.

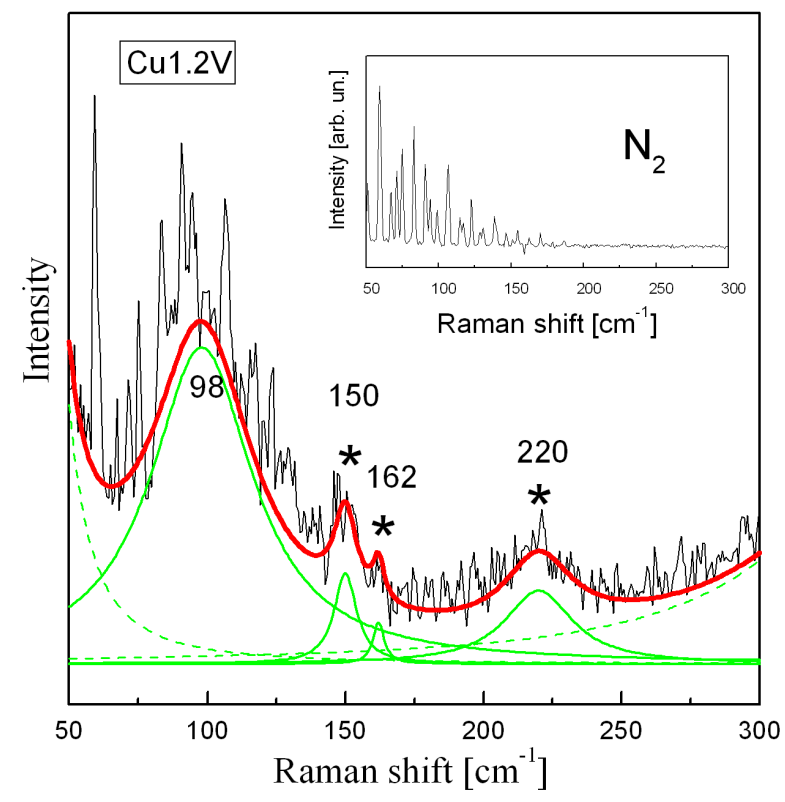

Fig. 2. Raman spectra of $\mathrm{Cu} 1.2 \mathrm{~V}$ sample. Inset: Raman spectra of $\mathrm{N}_{2}$.

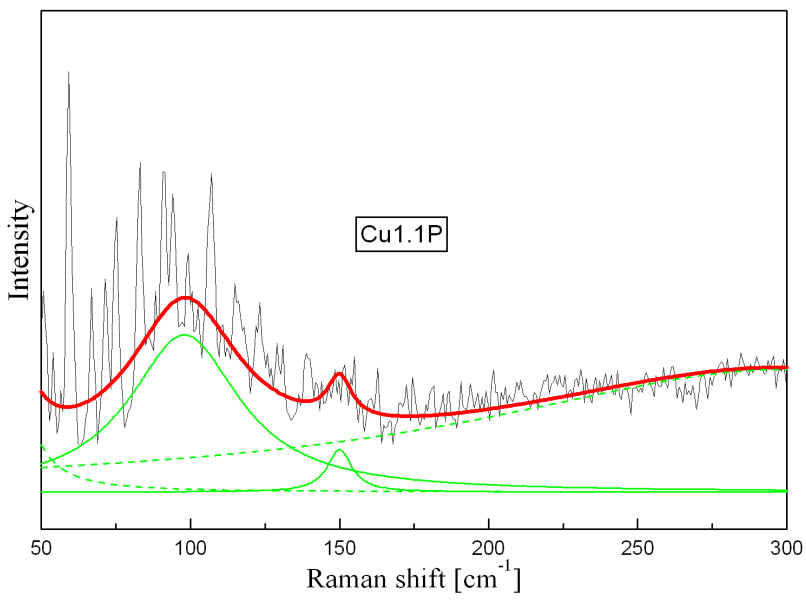

Fig. 3. Raman spectra of $\mathrm{Cu} 1.1 \mathrm{P}$ sample.

The Raman spectra of $\mathrm{Cu} 1.2 \mathrm{~V}$ and $\mathrm{Cu} 1.1 \mathrm{P}$ are presented in Figs. 2 and 3 . In addition to a very narrow lines (with a width of $\approx 2 \mathrm{~cm}^{-1}$ ), two types of lines are clearly visible in spectra: narrow $\left(\approx 7 \mathrm{~cm}^{-1}\right)$ and wide $\left(\approx 40 \mathrm{~cm}^{-1}\right)$ lines. To demonstrate the nature of these very narrow lines in the range up to $120 \mathrm{~cm}^{-1}$, the spectrum of nitrogen is given on the insert of Fig. 2. It is obvious that the positions of these narrow lines from the insert match corresponding lines registered in the spectrum in Figs. 2 and 3. So it can be concluded that they are the parasite lines. Narrow lines are well defined, so we used deconvolution method in the wide lines analysis. 
Raman scattering spectra are often analyzed with help of a Lorenzian function or by the convolution of a Lorenzian and Gaussian curves. As the quality of the spectra in Figs. 2 and 3 is such that it allows only for a qualitative analysis with a partial discussion of the trend, we took that all lines are of the Lorenzian type. A typical line shape obtained in this way is also shown in Figs. 2 and 3. Dashed lines correspond to the Rayleigh scattering [6] and luminescence. Well resolved peaks appear at about $98,150,162$ and $220 \mathrm{~cm}^{-1}$ for the sample $\mathrm{Cu} 1.2 \mathrm{~V}$ (Fig. 2) and at 98 and $150 \mathrm{~cm}^{-1}$ for the sample $\mathrm{Cu} 1.1 \mathrm{P}$. Differences in the spectra originated from the different deformation.

Narrow lines, which are marked by stars in Fig. 2, originated from the $\mathrm{Cu}$ and $\mathrm{CuO}$ crystal structures. Appearance of $\mathrm{CuO}$ modes, as we have already said, is a consequence of the oxygen penetration in the sample. The registered lines originate from $\mathrm{Cu}-\mathrm{Cu}$ and $\mathrm{Cu}-\mathrm{O}$ [5]. Wide line is a consequence of amorphous state. Namely, wide line at $98 \mathrm{~cm}^{-1}$ originated from $\mathrm{CuO}$ that become amorphous. In this range $\mathrm{CuO}$ phonon states density is large [5], and therefore line is no more narrow.

Mode at $220 \mathrm{~cm}^{-1}$ is probably a consequence of multiphonon process. The absence of those structure in the $\mathrm{Cu}$ 1.1P Raman spectra points to influence of material treatmens on the structure of $\mathrm{Cu}$ and $\mathrm{CuO}$. Existence of two types of lines indicates that in the specimen exists nano-sized crystal structures of both $\mathrm{Cu}$ and $\mathrm{CuO}$ related with three dimensional amorphous boundary spaces, which indicates that the plastic deformation of the sample did not lead to total amorphisation of the specimen.

\section{Conclusion}

Results of Raman measurements of plastically deformed copper are presented. Two types of lines: narrow (with width of $\approx 7 \mathrm{~cm}^{-1}$ ) and wide $\left(\approx 40 \mathrm{~cm}^{-1}\right)$ are registered. The presence of two types of lines indicates that in the specimen exists nano-sized crystal structures of both $\mathrm{Cu}$ and $\mathrm{CuO}$ related with three dimensional amorphous boundary spaces. Obtained results indicated that that plastic deformation of the sample did not lead to total amorphisation of the specimen.

\section{Acknowledgments}

This work was supported under the Program of Scientific and Technological Cooperation between Republic Slovenia and Republic Serbia. Work in Serbia is supported by Serbian Ministry of Science and Technological Development under Project 141028B. This paper is part of a Slovenian MNT ERA-NET Project no. 3211-07-000023: Nano Structured Metal Ceramic Composites.

\section{References}

[1] N. Habbache, N. Alane, S. Djerad, L. Tifouti, Chemical Engineering Journal 152, 503 (2009).

[2] G. Karim-Nezhad, R. Jafarloo, P. Seyed Dorraji, Electrohimica Acta 54, 5721 (2009).

[3] W.F. Smith, J. Hashemi, in: Foundations of Materials Science and Engineering., McGraw-Hill Professional, 2003, p. 223.

[4] W. Chambers, R. Chambers, Chambers's Information for the People. L (5th ed.), W. \& R. Chambers, 1984, p. 312.

[5] G. Kliche, Z.V. Popovic, Phys. Rev. B 42, 1060 (1990).

[6] B.N. Henry, in: Raman Spectroscopy: Sixty Years On, Ed. J.R. During, Vol. 10, Elsevier, Amsterdam 2008. 